\title{
Research on Changes of Oil Moisture, Acid Value, Furfural and Insulation Paper Polymerization Degree of Oil-paper Insulation under Accelerated Thermal Aging
}

\author{
Guoxing $\mathrm{Li}^{1, \mathrm{a}, *}$, Lin $\mathrm{Li}^{1, \mathrm{~b}}$, Yue Wang ${ }^{1, \mathrm{c}}$ and Rui Zhang ${ }^{1, \mathrm{~d}}$ \\ ${ }^{1}$ State Grid Heilongjiang Electric Power Company Limited Electric Power Research Institute, Xiangjiang \\ Street, Harbin, Heilongjiang Province, China

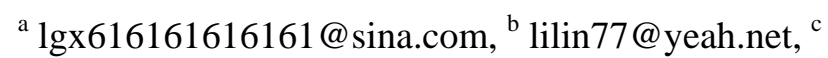 \\ wangyue_chn@163.com, dzhangr@hepri.hl.sgcc.com.cn \\ *corresponding author
}

Keywords: Oil-paper Insulation, Accelerated Thermal Aging, Moisture, Acid Value, Furfural, Polymerization Degree.

\begin{abstract}
It was discovered that there was prominent interaction among transformer oil moisture content, acid value, furfural content and insulation paper polymerization degree during monitoring of transformer operation. Therefore, insulation paper aging and furfural generation under the action of thermal energy and moisture, insulation paper polymerization degree decline law, change of moisture content in oil and acid value with aging time were studied through laboratory accelerated thermal aging test in the paper. Test results were analyzed. Change and interaction laws of four test items within the thermal aging test cycle were obtained initially, thereby providing reference for detecting furfural content in transformer oil and judging aging degree of solid insulation paper.
\end{abstract}

\section{Introduction}

Transformer is key, important and expensive electric equipment in power grids. Its reliability is related to safe and reliable operation of electric power systems directly ${ }^{[1]}$. The insulation of oilimmersed power transformers is mainly composed of oil and paper (paperboard). Defect, failure and damage of oil-paper insulation systems are main reasons of transformer faults. Therefore, the oil-paper insulation system is always regarded as the lifeline of transformers ${ }^{[2]}$ 。

Insulation paper fiber can be aged and decomposed gradually from insulation paper (paperboard) immersed in the transformer oil to generate a series of oxygen heterocyclic compounds under the action of high-intensity electric field, relatively high temperature, air and trace moisture, wherein furan formaldehyde (namely furfural) is one of main degradation products of insulation paper ${ }^{\text {[3] }}$. Though insulation paper can be aged, and the content of furfural dissolved in oil can be reduced in actual operation of transformers due to oil replacement, oil filtering, absorption of on-line oil purifier, etc. ${ }^{[4]}$, furfural content in transformer oil still has important reference significance for judging aging degree of insulation paper (paperboard).

It was found there was obvious interaction transformer oil moisture, acid value, furfural content and insulation paper polymerization degree during operation monitoring. The research result of Allan ${ }^{[5]}$ and H. Kan ${ }^{[6]} \mathrm{H}$ showed that temperature had low influence on furfural distribution proportion in oil paper. Prof. Liao Ruijin studied molecular dynamics about the influence of transformer oil moisture on furfural spreading and distribution ${ }^{[7]}$, and the action law of moisture on furfural distribution was initially obtained. Hohlein ${ }^{[8]}$ discovered the follows in the solid insulation system aging test under transformer operation temperature that the logarithmic relationship between furfural content in oil and insulation paper polymerization degree might be changed at different moisture contents. It was believed that moisture had great influence on the furfural distribution in oil paper. In the paper, changes of transformer oil moisture, furfural, acid value and insulation paper polymerization degree were studied under the condition of accelerated thermal aging. The system composed of mineral insulating oil and special insulation paper for transformer winding was 
adopted as an object for studying insulation paper aging and furfural generation, decrease law of insulation paper polymerization degree and change of moisture content in oil and acid value with aging time under the action of thermal energy and moisture, thereby providing reference for detecting furfural content in transformer oil and judging aging degree of solid insulation paper.

\section{Thermal Aging Test}

\subsection{Testing Materials}

New naphthenic mineral insulating oil with freezing point lower than $-45^{\circ} \mathrm{C}$, winding insulation paper and copper strap wire provided by one transformer manufacturer were adopted for testing. A $100 \mathrm{~mL}$ glass syringe was selected as the test vessel, and the test vessel was wrapped by a layer of silver paper for isolating external light.

\subsection{Sample Preparation}

The composition of the transformer oil-paper insulation system was simulated. Test samples with oil-paper mass ratio of about 10:1 were prepared, wherein the copper metal area in oil 1.0mL was about $0.2 \mathrm{~cm}^{2}$.

1) Cut several insulation paper samples with width of $12 \mathrm{~mm}$ and mass of $4 \mathrm{~g} \pm 0.1 \mathrm{~g}$, put them in a vacuum chamber, dry for $48 \mathrm{~h}$ at $90{ }^{\circ} \mathrm{C}$, make their moisture content below $0.5 \%$ (mass ratio), cool insulation paper samples naturally cooling to $25{ }^{\circ} \mathrm{C}$ or so, immerse the samples in new insulating oil (the moisture content of new oil was less than $5 \mathrm{mg} / \mathrm{kg}$ ) for $12 \mathrm{~h}$.

2) Design and process a simulation transformer with volume of about 78.6L without equipment of iron core and other parts, produce one shell only. Inject new insulating oil about 50L into the simulation transformer, adjust the moisture content in the transformer oil through vacuum degassing, and set the air content in the insulating oil lower than $1 \%$ (volume ratio).

3) Cut several copper strap wires with length of $125 \pm 1 \mathrm{~mm}$, roll them (roll diameter was less than the inner diameter of $100 \mathrm{~mL}$ glass syringe by about $3 \mathrm{~mm}$ ), clean them with n-hexane, and dry them;

4) Add an above-mentioned paper sample and a copper strap wire roll into a clean and dry $100 \mathrm{~mL}$ glass syringe, insert the syringe core, and weigh the syringe.

5) Collect insulating oil in the simulation transformer through a sealed sampling mode by the syringe in 4) to $50 \mathrm{ml}$ calibration tail in the syringe, cover the silicone rubber sealing cap, weight the collected oil sample by the weight loss method, then wrap the syringe by silver paper, and record syringe number, paper sample mass, oil sample mass, oil sample moisture content and air content.

6) Prepare several test samples with moisture contents of $5.2 \mathrm{mg} / \mathrm{L}, 10.5 \mathrm{mg} / \mathrm{L}, 21.2 \mathrm{mg} / \mathrm{L}, 30.6$ $\mathrm{mg} / \mathrm{L}$ and $41.5 \mathrm{mg} / \mathrm{L}$ in the insulating oil as the above-mentioned steps.

\subsection{Thermal Aging Test}

Contain prepared test samples in $110{ }^{\circ} \mathrm{C}, 130{ }^{\circ} \mathrm{C}$ and $150{ }^{\circ} \mathrm{C}$ electric heating blowing dry oven respectively for high temperature accelerated thermal aging test, take out three test samples under the same aging state at certain time interval during test, measure moisture content in oil immediately (not open the silver paper wrapped outside the syringe), place the sample in the test room for 12 hours, open the silver paper, determine the moisture content, acid value and furfural content of oil samples, and measure the polymerization degree of insulating paper, and regard the average value of the measurement results of the three samples as the result.

\section{Analysis of Test Results}

\subsection{Change of Moisture Content in Oil with Aging Time}

Fig. 1 shows the changing curve of moisture content in test sample oil with aging time under oil initial moisture content of $5.2 \mathrm{mg} / \mathrm{L}$. Fig. 1 indicates that the moisture content in oil presented fluctuating changes with aging time during measurement at laboratory temperature. The 
temperature was higher, the fluctuation of moisture content was greater. The moisture content in oil presented gradual increase trend as a whole with occasional fluctuation during measurement at aging temperature. In addition, the measurement result of moisture content in oil at aging temperature was much higher than that at laboratory temperature.

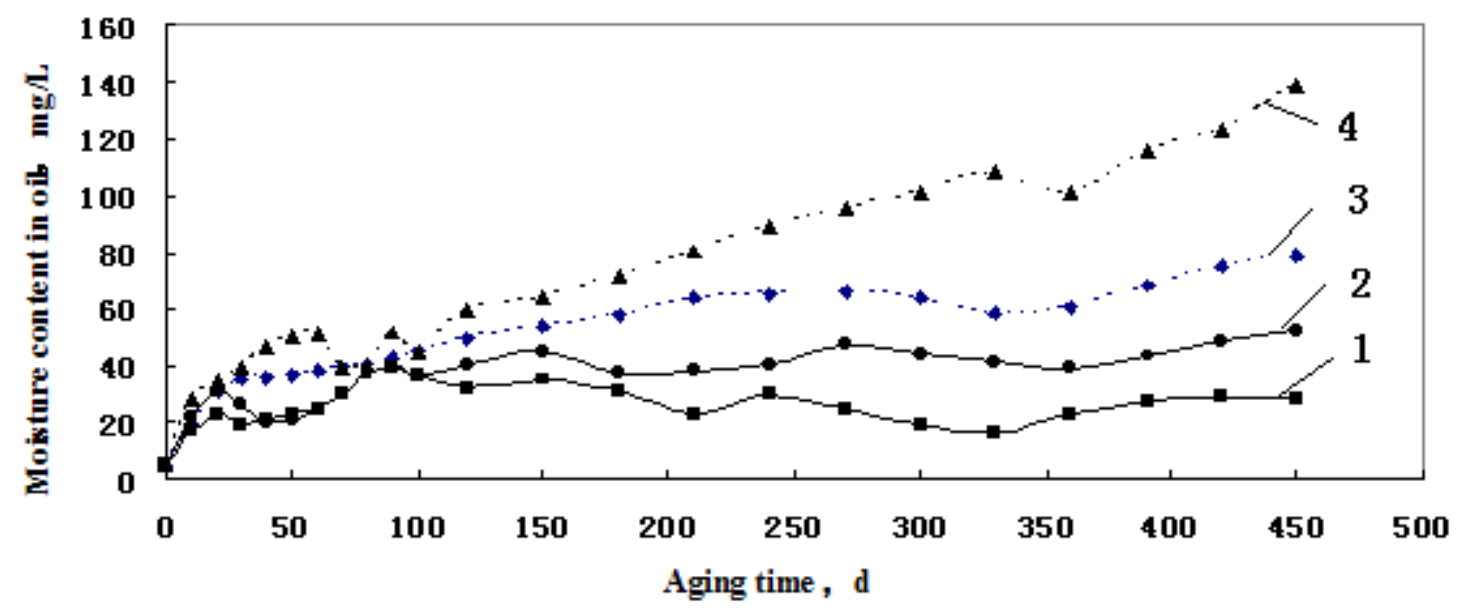

$1-110^{\circ} \mathrm{C}$, measurement at laboratory temperature $; 2-150^{\circ} \mathrm{C}$, measurement at laboratory temperature $; 3-110^{\circ} \mathrm{C}$, measurement at test temperature $; 4-150^{\circ} \mathrm{C}$, measurement at test temperature

Figure 1 Changing curve of moisture content in test sample oil with aging time under oil initial moisture content of $5.2 \mathrm{mg} / \mathrm{L}$.

Since the mineral insulating oil was a mixture composed of various hydrocarbon compounds ${ }^{[9]}$, water molecule belonged to polar molecule, it was generally difficult to dissolve the water molecule into mineral insulating oil, and the solubility of water molecule in mineral insulating oil was sharply increased with temperature rise, more moisture can be dissolved in high temperature insulating oil within the same aging time. Oil temperature was reduced gradually, moisture in oil was transferred into insulation paper when test samples were placed in the laboratory, thereby decreasing the moisture content in oil dramatically.

Moisture did not react with insulating oil chemically during aging. However, moisture also had very strong affinity to oil molecules. In addition, the oil aging degree was deeper, the polarity degradation products were more, the solubility of water in aging oil was larger, and the moisture content in oil was higher with aging time.

\subsection{Change of Furfural Content in Oil}

\subsubsection{Influence of Temperature on Furfural Generation}

Fig. 2 shows the changing curve of furfural content in oil with aging time at different aging temperatures. Fig. 2 indicates that the furfural content in oil was gradually increased with aging time. The temperature was higher, the furfural content in oil was higher. It is obvious that furfural generation due to insulation paper cellulose degradation was greatly influenced by temperature. The furfural content in aging test sample oil was rapidly increased at $150^{\circ} \mathrm{C}$ when aging lasted for $40 \mathrm{~d}$. Rapid aging decomposition was discovered in the insulation paper. 


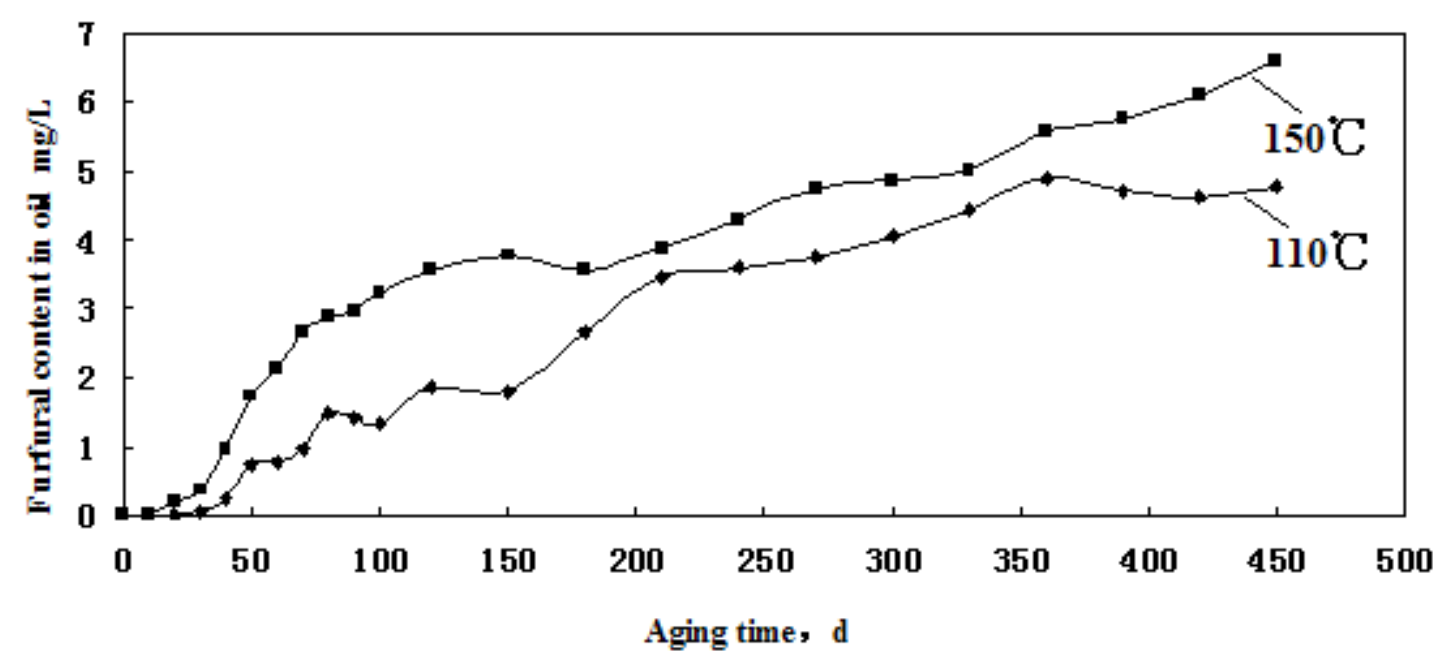

Figure 2 Changing curve of furfural content in oil with aging time at different aging temperatures in test samples with oil initial moisture content of $5.2 \mathrm{mg} / \mathrm{L}$.

\subsubsection{Influence of Moisture in Oil on Furfural Generation}

Fig. 3 shows the change of furfural content in insulating oil with aging time under $110^{\circ} \mathrm{C}$ aging temperature aiming at test samples of different initial moisture contents.

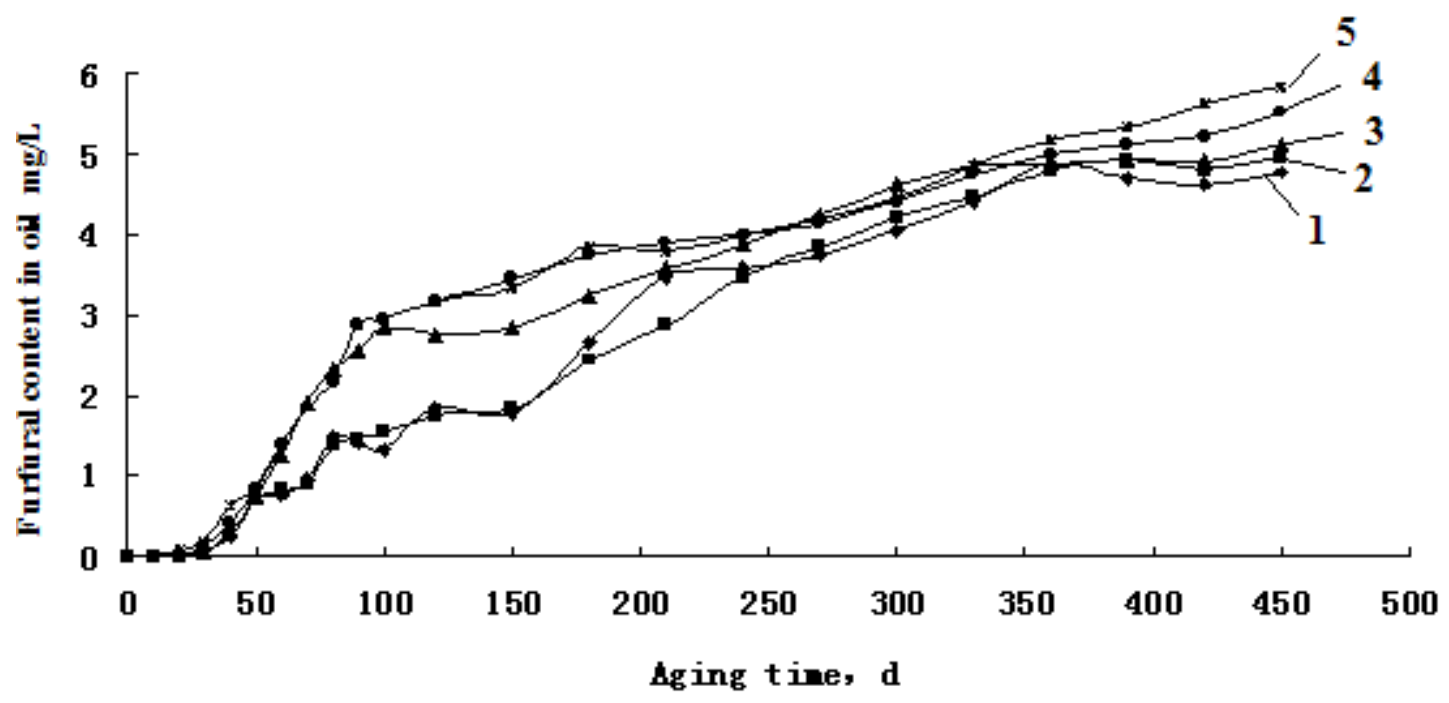

1-5.2mg/L initial moisture content ; 2-10.5mg/L initial moisture content ; 3-21.2mg/L initial moisture content ; 4-30.6mg/L initial moisture content ; 5-41.5mg/L initial moisture content

Figure 3 Changing curve of furfural content in insulating oil with aging time under $110^{\circ} \mathrm{C}$ aging temperature aiming at test samples of different initial moisture contents.

Test results show that moisture content in oil can promote generation and dissolution of furfural. Firstly, water molecule penetrated through cellulose long molecules when the moisture content in the insulation paper was high. Cellulose polymeric chain was ruptured, and hydrolysis reaction occurred. The moisture was more, cellulose hydrolysis was faster, and more furfural was produced and dissolved in oil. Secondly, the moisture content in oil was higher in the oil-paper insulation system, more furfural entered into oil to form a hydrogen bond with moisture in oil, and the solubility of furfural in mineral oil containing moisture was further improved conversely.

\subsection{Change of Insulation Paper Polymerization Degree}

Fig. 4 shows the change of polymerization degree of test samples with aging time at different temperatures when oil initial moisture content was $10.5 \mathrm{mg} / \mathrm{L}$. Fig. 4 indicates that the insulation paper polymerization degree was decreased rapidly at the beginning under the action of thermal 
energy. The decreasing speed was decelerated after certain time. The temperature was higher, the decreasing speed of the polymerization degree was rapider, and the polymerization degree value at the end of aging was smaller. The conclusion was consistent with that in literature ${ }^{[10]}$. It was believed in analysis that insulation paper was mainly composed of cellulose, lignin and hemicellulose ${ }^{[11]}$, and cellulose belonged to a two-phase system composed of crystalline region and amorphous region which were crossed and connected. The cellulose long-chain penetrated through crystalline region and amorphous region. In amorphous region, the intermolecular force was weaker since molecular arrangement was looser, which can be ruptured more easily. In crystalline region, the molecular arrangement was tight, the bond energy was relatively strong, and large energy was required for rupturing the cellulose chain. Therefore, cellulose degradation reaction mainly occurred in the amorphous region with fast speed at the beginning of insulation paper aging. However, the amorphous region in the insulation paper was consumed gradually with deepening of reaction. The degradation reaction extended to the crystalline region. The crystalline region was stable relatively, and the insulation paper degradation rate was decreased gradually.

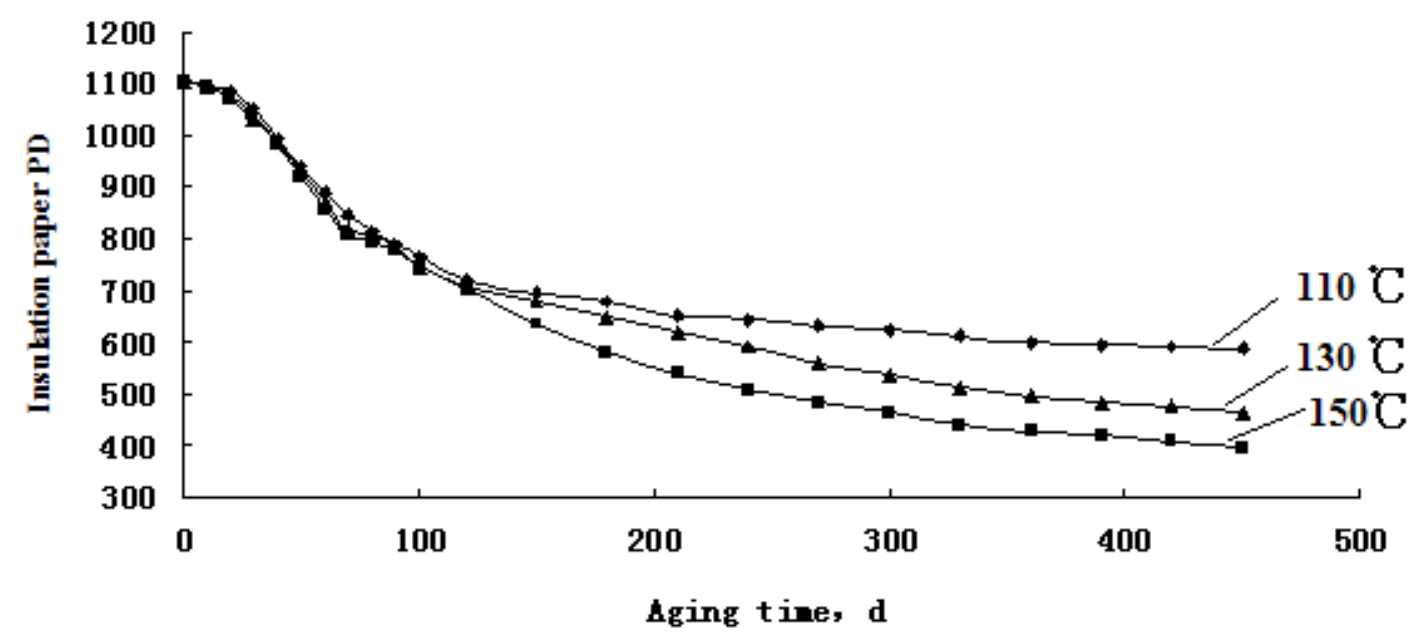

Figure 4 Changing curve of polymerization degree of test samples with aging time at different temperatures when oil initial moisture content was $5.2 \mathrm{mg} / \mathrm{L}$.

The test results show that thermal energy can promote insulation paper degradation greatly. Therefore, operation temperature should be controlled well in actual operation of the transformer, and the service life can be prolonged.

\subsection{Change of Insulating Oil Acid Value}

Fig. 5 shows the change of oil acid value of test samples with aging time at different aging temperatures when the oil initial moisture content was $5.2 \mathrm{mg} / \mathrm{L}$. The acid value of the insulating oil was increased gradually with progress of the aging test, but the value was relatively low, which was lower than $0.1 \mathrm{mgKOH} / \mathrm{g}$. It is believed in analysis that hydrocarbon substances in the mineral insulating oil were aged and decomposed to produce carbonoperoxoic acid with low molecular weight mainly ${ }^{[12]}$. The carbonoperoxoic acid can be absorbed on the insulation paper easily, and the acid content in oil was low. Therefore, oil acid value was gradually increased in the aging process, the value was still at lower level, and its correlation with moisture content in oil, furfural content and insulation paper polymerization degree was insignificant. 


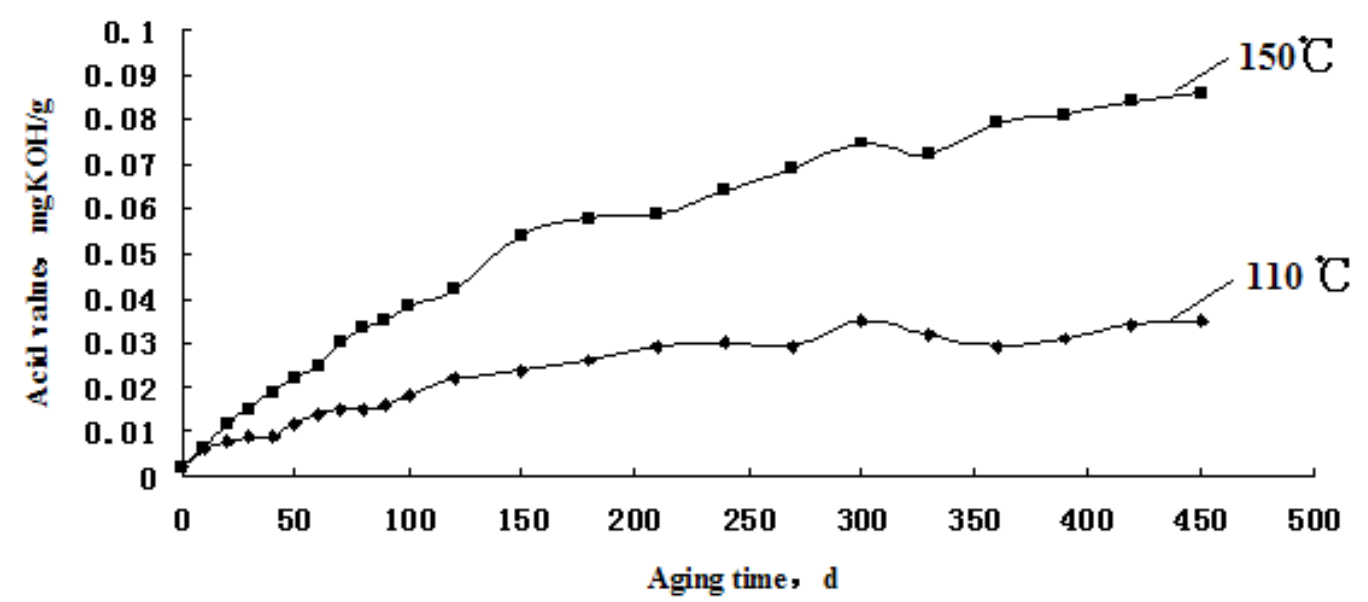

Figure 5 Changing curve of oil acid value of test samples with aging time at different aging temperatures when the oil initial moisture content was $5.2 \mathrm{mg} / \mathrm{L}$.

\section{Conclusion}

In the paper, changes of moisture content in oil, furfural content, oil acid value and insulation paper polymerization degree with aging time under the action of thermal energy and moisture in an insulation system are concluded through laboratory accelerated thermal aging test, wherein the insulation system is composed of mineral insulating oil and insulation paper. The results provide significant reference for operation monitoring and analysis of the items. Concrete conclusions are shown as follows:

1) More moisture can be dissolved in high temperature insulating oil within the same aging time. Oil temperature was reduced gradually, and moisture in oil is transferred into the insulation paper when test samples were placed in the laboratory. The moisture content in oil at the aging temperature was much higher than that at the laboratory temperature. The oil aging degree is deeper, the polar degradation products are more, and the water solubility in aging oil is greater.

2) Furfural generation due to insulation paper cellulose degradation is greatly influenced by temperature. The temperature is higher, the insulation paper degradation speed is faster, furfural content in oil is also higher. Moisture content in oil also can promote furfural generation and dissolution.

3) Thermal energy can promote insulation paper degradation greatly. The insulation paper polymerization degree is decreased rapidly at the beginning under the action of thermal energy. The decreasing speed is decelerated after certain time. The temperature is higher, the decreasing speed of the polymerization degree is rapider, and the polymerization degree value at the end of aging is smaller. Therefore, the operation temperature should be controlled well during actual operation of the transformer, and the service life thereof can be prolonged.

4) The oil acid value was increased gradually with progress of the aging test, but the value was relatively low, which was lower than $0.1 \mathrm{mgKOH} / \mathrm{g}$. The acid value has no prominent correlation with moisture content in oil, furfural content and insulation paper polymerization degree.

\section{References}

[1] GU Xiao-bo, ZHANG Yi-jun. (2010) Research and application of insulation ageing for power transformer based on frequency domain spectroscopy [J]. Zhejiang Electric Power, (1): 13-17.

[2] YIN Ke-ning. (2003) Theory of transformer design [M]. Beijing, China: China Electric Press.

[3] YU Yuan-hai, ZHANG Biao. (2002) The research of relation between concentration of furan and aged of papers [J]. East China Electric Power, (11): 16-18.

[4] LI Guo-xing, JIANG Zi-qiu, YAO Bin-fang. (2001) Study of the effect of the thermosiphon 
bypass running on the furfurol content in the transformer oil [J]. High Voltage Engineering, 27 (1): 59-62.

[5] Allan D M. (1997) Recent advances in the analysis and interpretation of aged insulation from operating power transformers[C]//Proceedings of the 5th International Conference on Properties and Applications of Dielectric Materials. Seoul, Korea: [S.n.].

[6] Kan H, Miyamoto T, Makino Y, et a1. (1994) Absorption of CO2 and CO gases and furfural in insulating oil into paper insulation in oil immersed transformers [C]//Conference Record of the 1994 IEEE International Symposium on Electrical Insulation. Pitts-burg. USA: IEEE, 4144.

[7] LIAO Rui-jin, ZHOU Xin, YANG Li-jun, et a1. (2011) Impacts of water within transformer oil on the diffusion and distribution characteristics of furfural by molecular dynamics [J]. High Voltage Engineering, 37 (6): 1321-1328.

[8] Hohlein I, Kachler A J. (2005) Ageing of cellulose at transformer service temperature, part 2: influence of moisture and temperature on degree of polymerization and formation of furanic compounds in free breathing systems [J]. IEEE Electrical Insulation Magazine, 21(5): 20 -24.

[9] LIU Feng-lin, XU Wei. (2004) Characteristic comparison between papaffine-base and naphthene-base transformer oils[J]. Transformer, 41(27): 27-30.

[10] ZHANG Yu-xiao, LI Sheng-li, WANG Meng-jun, XU Xiao-yu. (2011) Degree of polymerization of insulation paper in the transformer [J]. High Voltage Engineering, 37 (10), 24582462.

[11] Emsley A M, Xiao XHeywood R J, et a1. (2000) Degradation of cellulosic insulation in power transformers, part 3: effects of oxygen and water on ageing in oil[J]. IEE Proc-Sci Meas Technol, 147(3): 115-119.

[12] G. Harry. (2012) Hydrolysis Process in PLN P3BJB Transformers as an Effect of Oil Insulation Oxidation [M]. 2012 IEEE International Conference on Condition monitoring and Diagnosis. Bali, Indonesia. 1147-1150. 